\title{
Desenho e ANTROPOLOGIA: RECUPERAÇÃo hISTÓRICA E MOMENTO ATUAL
}

Aina Azevedo ${ }^{1}$

UFRN, Natal-RN, Brasil

\begin{abstract}
Por que os antropólogos desenhavam e por que pararam de fazê-lo? Com questões como essas em mente, o presente artigo busca percorrer e recuperar de forma fragmentária partes de uma possivel história do desenho na antropologia, bem como os regimes de visualidade que a atravessam, com o objetivo de apresentar o estado da arte da relação entre desenho e antropologia em torno do século XXI. Como observa Ballard (2013), assistimos a uma "virada gráfica" no presente, quando diversos antropólogos voltam a desenhar, renovando nossas perguntas iniciais: por que alguns antropólogos desenham atualmente e quais são os efeitos dessa prática em suas metodologias/resultados de pesquisa? Ao levantar tais questões, este artigo pretende iluminar os caminhos passados, atuais e, quiçá, futuros do desenho na antropologia.
\end{abstract}

Palavras-chave: desenho, antropologia gráfica, métodos, visualidade

\section{Desenho e Antropologia: recuperação histórica e momento atual²}

\author{
A mão é ação, ela cria e, \\ por vezes, seria o caso \\ de dizer que pensa.
}

Henri Focillon, Elogio da Mão

Os desenhos feitos por antropólogos têm uma história passada e atual pouco conhecida na antropologia, tanto é que, na maior parte das vezes, a menção ao assunto é prontamente mal

$1 \quad$ Aina Azevedo é doutora em antropologia pela Universidade de Brasília, fez pós-doutorado na University of Aberdeen, Escócia, e trabalha atualmente como professora substituta na Universidade Federal do Rio Grande do Norte, Brasil. Contato: ainaazevedo@gmail.com.

2 A pesquisa bibliográfica que deu origem a este artigo foi desenvolvida durante o estágio de pós-doutorado na University of Aberdeen. Agradeço à CAPES pela bolsa que viabilizou tal projeto de pesquisa e, consequente- 
interpretada como uma variação de interesses relacionados a tudo (cultura visual, grafismo indígena, pintura corporal, pintura rupestre, grafite, antropologia visual, etc.), menos aos desenhos feitos por antropólogos. A ideia de antropólogos desenharem parece causar algum incômodo, como é o caso expresso no questionamento sobre o valor de tais desenhos - algo que não ocorreria, acaso tratássemos de fotografias feitas por antropólogos, por exemplo. Entretanto, quando se faz uma reflexão mínima, percebe-se que não há nada tão diferente assim em desenhar. Conhecidos de todos nós são os desenhos relacionados à cultura material e à anatomia feitos por antropólogos no passado. O que parece estranho, afinal, é sabermos tão pouco sobre esses desenhos. Em consequência, temos uma história desconhecida a sustentar um presente que nos parece duvidoso.

Um belo exemplo de monografia amplamente conhecida e desenhada é o "Os Nuer" de Evans-Pritchard (2002). Decerto, os desenhos de vacas, cabaças, lanças, etc., jamais causaram incômodo algum: são desenhos sóbrios que, a exemplo dos "sonhos sóbrios" distinguidos por Freud, não precisam ser interpretados por terem uma relação auto-evidente com o que representam (Freud 2015: 130). Entretanto, mesmo em casos como esses, uma investigação mais séria pode ser reveladora, como será demonstrado posteriormente no trabalho de Geismar (2014) sobre os desenhos de Bernard Deacon.

Talvez fosse o caso de nos perguntarmos, então, por que os antropólogos desenhavam e por que pararam de fazê-lo? Com questões como essas em mente, o presente artigo busca percorrer e recuperar de forma fragmentária partes de uma possível história do desenho na antropologia, bem como os regimes de visualidade que a atravessam, com o objetivo de apresentar o estado da arte da relação entre desenho e antropologia em torno do século XXI. Como observa Ballard (2013: 139), persiste uma ausência de histórias sobre o desenho na antropologia, a despeito de sua importância na produção do conhecimento. Entretanto, o momento atual the parece bastante confortável para antropólogos que desenham, quando ocorre um "graphic turn" ou "virada gráfica" que, em suas palavras, indica "o renascimento do interesse pelo desenho como uma atividade e foco analítico entre antropólogos e em outras disciplinas” (Ballard 2013: 140) [Tradução minha $]^{3}$. Ao perceber que diversos antropólogos voltam a desenhar, renovamos também nossas perguntas iniciais: por que alguns antropólogos desenham atualmente e quais os efeitos dessa prática em suas metodologias/resultados de pesquisa? Ao levantar tais questões, este artigo pretende iluminar os caminhos passados, atuais e, quiçá, futuros do desenho na antropologia ${ }^{4}$.

\section{LoCALIZANDO O DESENHO NA HISTÓRIA DA ANTROPOLOGIA}

Como não há futuro sem passado, começo com breves notas históricas sobre o lugar do desenho na antropologia, ciente, por um lado, do coro que silencia diante dessa localização e, por outro, da insuficiência das notas que apresento. Fruto da aproximação ao tema do desenho feito por antropólogos na atualidade, o presente artigo inevitavelmente recuperou reflexões im-

mente, o presente artigo.

3 Ao longo do artigo há diversas traduções feitas por mim - o que pode ser notado quando a referência é em língua inglesa ou espanhola e a citação em língua portuguesa.

4 Seria muito oportuno trazer uma série de desenhos no transcorrer do texto, entretanto, a reprodução dos mesmos se fez impossível pela questão dos direitos autorais. 
portantes sobre o desenho na história da antropologia. Apresentadas aqui como breves notas históricas - um tanto fragmentárias -, tais informações não pretendem outra coisa que não seja levantar pistas e reflexões sobre os caminhos de aparição e exclusão do desenho na antropologia. A falta de rigor que por ventura seja identificada nesse percurso se deve, portanto, a um investimento menor e ainda inicial a um tema vasto e pouco debatido.

Prontamente, é possível identificar um protagonista na relação histórica entre desenho e antropologia: o desenho conhecido como etnográfico que representa a vertente genuinamente antropológica do desenho, cuja história, mais uma vez, ainda está por ser feita. Aqui, seria o caso de fazer uma pausa a respeito do termo "desenho etnográfico" que parece dizer tanto e, ao mesmo tempo, tão pouco sobre si mesmo. Tanto, se levarmos em conta a distinção que celebra: um tipo especial de desenho, porque feito por etnógrafos em trabalho de campo; tão pouco, por essa distinção remeter mais a uma época remota da antropologia e a um estilo vago que leva a reboque uma série de denominações, tais como: desenhos de cultura material, desenhos anatômicos, esboços nos diários de campo e retratos - para nomear suas maiores expressões e especialismos, sem que isso signifique dizer muita coisa.

Seja como for, o "desenho etnográfico" existe, porém de forma subsidiária, enfeitando livros, muitas vezes, sem dispormos sequer do nome de seus autores. Aparentemente pouco interessante, o "desenho etnográfico" expressa um particularismo antropológico, cuja particularidade, entretanto, nos é desconhecida. Outras formas de notação, presentes também em abundância na antropologia, como diagramas e gráficos de parentesco, surgem e desaparecem com igual desinteresse. Não é casual, portanto, a falta de um verbete sobre o desenho - mesmo o etnográfico - em enciclopédias da magnitude de "The Routledge Encyclopedia of Social and Cultural Anthropology" (Barnard e Spencer 2010).

Finda a pausa, retornemos para os trabalhos em que encontramos reflexões sobre o desenho. Em termos de uma recuperação histórica do desenho feito por antropólogos, há alguns esforços importantes que merecem destaque, como o trabalho de Geismar (2014) sobre os desenhos nos diários de Bernard Deacon - antropólogo britânico que fez trabalho de campo em Vanuatu, na Melanéseia, entre 1926 e 1927. Geismar interessou-se em analisar os desenhos nos diários de Deacon partindo do princípio de que as páginas em branco não haviam sido preenchidas ao acaso, ou seja, sem uma intencionalidade. Para a autora, o que vemos nos desenhos de Deacon é aquilo que ele mesmo estava buscando: "Os esboços de Deacon nos ensinam não apenas sobre aquilo que ele estava vendo, e talvez pensando, mas também sobre como ele foi treinado a ver e pensar, tanto pelos seus professores em Cambridge quanto pelos seus interlocutores Malakulan." (Geismar 2014: 98). Assim, Geismar revela que seu interesse pelos desenhos buscava tanto a subjetividade de Deacon, quanto as formas particulares de se treinar o olhar, ou, nas suas palavras, de se treinar o "como ver" (2014: 97).

Do mesmo modo, Ballard (2013) dedicou-se aos desenhos do antropólogo russo do século XIX, Nikolai Miklouho-Maclay, que também fez pesquisa em Vanuatu, na Melanésia - assim como o próprio Ballard. Neste caso, Ballard interessou-se pelos desenhos de Miklouho-Maclay como uma forma de comunicação importante empregada pelo antropólogo na Oceania, na falta, inclusive, de uma língua comum. Entretanto, Ballard vai além de uma pesquisa histórica e reflete sobre um debate paralelo à temática do desenho que é a repatriação dos retratos. Além disso, o autor destaca o uso ostensivo de desenhos anteriormente não só por Miklouho-Maclay, 
como demonstrado nas publicações das notas de campo e etnografias de "Bernand Deacon (1934), F.E. Williams (1936), John Layard (1942) e Jack Taylor (2008)” (Ballard 2013: 139).

Uma outra exceção que se debruça sobre os desenhos, é a introdução ao livro "Histórias Etíopes, Diário de viagem”, contribuição de Ramos (2010) à literatura que combina a investigação antropológica ao desenho. Aqui, o autor identifica algumas expedições e outras experiências em que houve uma "feliz e sistematizada simbiose" entre desenho e antropologia:

[...] os materiais da expedição Jesup à costa nordeste do Pacífico, coordenados por Franz Boas e ilustrados por Waldemar Bogoras e Rudolf Weber; os desenhos de Nikolai Miklouho feitos durante a sua estadia de vinte e um anos na Nova Guiné; as ilustrações dogon redesenhadas por Jean-Charles e Roger Sillans no Renard Pâle, de Marcel Griaule e Germaine Dieterlen; ou os desenhos de Robert Powell feitos durante um período de vinte e cinco anos no Nepal e no Ladhak. (Ramos 2010: 21-22)

Parte dessas experiências e expedições são bastante conhecidas e, mais ou menos, acessíveis. No entanto, me surpreendi ao constatar que o acervo de desenhos mais amplamente acessível porque on line - e além disso, catalogado por autor/lugar/período/etnia/expedição, é a coleção de desenhos etnográficos russos disponibilizada pelo museu Kuntskamera ${ }^{5}$ de São Petersburgo. Apesar da coleção não ter sido ainda objeto de estudo mais aprofundado, o desenho ocupa lugar de destaque ali. Aliás, um dado evidenciado não somente no museu, como veremos adiante.

Embora se saiba que anteriormente o desenho compunha o métier dos antropólogos, esse passado pouco conhecido (quando, por que e como desenhavam?) nos leva a formulações fáceis como a simples substituição do desenho pela fotografia. Certamente, essa ideia não é de todo falsa. Porém, com isso, perdemos a chance de pensar acerca dos regimes de visualidade - pretéritos e atuais - quando enfatizamos apenas a "evolução" de nossas técnicas de pesquisa. Isso para não mencionarmos a dimensão da habilidade dos antropólogos - um tema tão pouco discutido que chega a ser obscuro.

Como observa Geismar (2014) ainda sobre os desenhos de Deacon, desde a emergência do paradigma do trabalho de campo no final do século XIX, um conjunto de métodos era utilizado pelos antropólogos - entre eles, o desenho. Entretanto, ao contrário do que ocorreu com a fotografia, a coleta de objetos, as entrevistas e as genealogias, o desenho não foi totalmente desenvolvido como um método específico da etnologia. Desse modo, as habilidades de Deacon - assim como a dos antropólogos na atualidade, como bem observa Geismar - ficavam a cargo de um conhecimento pré-existente e oriundo de outras tradições, tais como a botânica, a arqueologia ou a ilustração de viagem (2014: 97).

Em contraponto, a antropologia desenvolvida no início do século XX no que viria a ser a União Soviética destacava em seus cursos de formação a aprendizagem de algumas técnicas de trabalho de campo, como andar a cavalo e desenhar (Makar'ev 1928) ${ }^{6}$. Evidentemente, isso

\footnotetext{
5 Os desenhos etnográficos da coleção do museu Kunstkamera se encontram no site: http://www.kunstkamera.ru/kunst-catalogue/index.seam?page=1\&c=ARTS

6 O livro em questão é um guia para etnógrafos em campo escrito antes da Segunda Guerra Mundial. O autor, Makar'er, tomou notas das aulas de Vladimir Bogoraz que lecionava o curso "Introdução à etnografia" na Leningrad State University, atual Saint Pertersburg State University. Agradeço ao amigo e colega Dmitry Vladimirovich Arzyutov por compartilhar comigo seu interesse pelo desenho russo, me apresentar o site do museu Kunstkamera, livros sobre o tema do desenho e ainda traduzir passagens do russo para o inglês, como foi o caso da presente referência.
} 
não explica o cuidado atual com o desenho na coleção do museu Kunstkamera mencionada anteriormente, mas indica a pioneira institucionalização do desenho como método de pesquisa e modo de exposição do conhecimento, justificando, em parte, o uso ostensivo do desenho na antropologia russa daquela época e ainda anteriormente. Eventualmente, uma pesquisa mais densa poderia encontrar referências ao ensino do desenho como parte das habilidades dos antropólogos na história da disciplina em outros países. Mas, por enquanto, parece ser a antropologia russa a que lhe deu maior destaque institucional ${ }^{7}$.

Ao tentar localizar o desenho na história da antropologia, muitas vezes, as informações são encontradas por meio de outros assuntos e histórias, já que uma preocupação explícita com o tema é uma novidade. Esse é o caso da antropologia visual que, apesar de apresentar uma trajetória distinta do desenho, é uma fonte valiosa de informação. Nessa história, o desenho atua como um discreto coadjuvante. Geralmente acionado para salientar que as imagens constituíram, desde o princípio, uma fonte inestimável de pesquisa antropológica, o desenho ressaltaria a naturalidade com que os estudos da/com a imagem deveriam ser incorporados à antropologia, dando corpo à institucionalização da antropologia visual ${ }^{8}$.

$\mathrm{Na}$ virada do século XIX para o XX, a difusão da imagem fotográfica e cinematográfica era destacada, por exemplo, pela conhecida expedição ao Estreito de Torres de 1898 - apenas 2 anos após a primeira exibição pública de cinema - quando foram produzidos pequenos filmes de populações autóctones fazendo fogo e dançando (Caiuby Novaes 2004; Barbosa e Teodoro da Cunha 2006). ${ }^{9}$ A partir daí, uma série de outros investimentos amplamente conhecidos irão corroborar a íntima relação entre antropologia e imagem, como é o caso das simetrias encontradas nas leituras das fotografias "totalizantes" de Malinowski, do retrato atemporal - com longos plano sequência - do filme Nanook of the North de Flaerthy, das sequências fotográficas do gestual balinês de Batson e Mead, da "verdade do filme etnográfico" de Jean Rouch, etc. (Barbosa e Teodoro da Cunha 2006).

Se, por um lado, não há uma continuidade mais profunda na recapitulação histórica que relacionaria o desenho aos subsequentes desenvolvimentos da antropologia visual, por outro, é verdade que a própria evolução histórica da antropologia visual não foi tão simples, nem linear. Ao entrarmos em contato com essa história, colhemos pistas sobre os regimes de visualidade da antropologia, cuja problematização feita pela antropologia visual, embora não possa ser transposta diretamente para a confecção de uma história do desenho, nos serve como guia.

Grimshaw e Ravetz procuram mostrar como o uso frequente de recursos visuais na antropologia vitoriana foi rechaçado na antropologia moderna. Conforme as autoras, os regimes de visualidade daquela antropologia eram marcados pela ostensiva utilização da imagem enquanto método e objeto de estudo para a classificação de pessoas nativas, dando forma ao esquema evo-

$7 \quad \mathrm{Na}$ atualidade, um exemplo bastante interessante que reúne o desenvolvimento de técnicas de desenho como parte da formação de estudantes de antropologia é apresentada por Kuschnir (2014). Trataremos desse assunto na próxima seção.

8 Aqui não nos aprofundaremos na antropologia visual e seus desdobramentos, bastando salientar que existe uma diferença entre antropologia visual e antropologia do visual. Conforme Martins (2012: 406), embora "exista uma antropologia do visual (Ruby 2005; Ribeiro 2004) que analisa sistemas e culturas visuais e as imagens ou produções visuais enquanto geradoras de significados (Ribeiro 2004), a antropologia visual que tem predominado assenta numa base metodológica na qual o filme etnográfico ou o documentário têm lugar central (Ruby 2005)”. 9 Um filme da expedição ao Estreito de Torres disponível em: https://www.youtube.com/watch?v=XuVDciKvJ0Q. 
lucionista então vigente. Posteriormente, a antropologia moderna buscaria se firmar enquanto uma disciplina científica e textual. Para tanto, seria imprescindível não confundi-la com o que Grimshaw e Ravetz chamam de "atividades rivais", como o jornalismo e o turismo, frequentemente associadas ao porte de uma câmera (2005: 5).

A exclusão de um tipo particular de imagem como modo de distinção da antropologia também é observada por Gell (1999: 31) com relação ao distanciamento dos gráficos - que, por sua vez, persistiam em ciências que ele denominou de "inimigas", como a engenharia. Para este autor, a antropologia de sua época era por definição não-diagramática e profundamente verbal, a exemplo de expoentes intelectuais como Geertz, Derrida, Ricouer e Heidegger (Gell 1999: 31). Gell também atribui este rechaço às imagens ao excesso de diagramas do estruturalismo, evidenciado em mentes que expressavam graficamente os significados da antropologia - como Leach, Lévi-Strauss e Fortes (Gell 1999: 31).

Seguindo com diagramas, uma rara menção feita aos mesmos em "The Routledge Encyclopedia of Social and Cultural Anthropology" ocorre no item "Tempo e espaço, prática e estrutura" que compõe o verbete "Tempo e Espaço" (Barnard e Spencer 2010: 689-693). Aqui, diagramas e que tais são descritos como um formalismo das análises estruturais para evidenciar uma análise virtual sincrônica (Barnard e Spencer 2010: 692). Entretanto, vejamos o que o próprio Gell tem a dizer sobre o assunto, valendo salientar que o autor usou diagramas não apenas para elucidar suas próprias reflexões (Gell 1975), como também para lançar luz à compreensão de outros trabalhos, a exemplo de "Strathernograms" (Gell 2006: 29-75). Desenhos e diagramas, apresentados ao longo de suas publicações, fazem todos parte de um mesmo esforço do autor de tornar a antropologia mais compreensiva visualmente ou, como escreve Gell, fazem parte da sua própria familiaridade com essa linguagem, evidenciada na sua maneira de pensar primeiro em diagramas, depois em textos escritos (Gell 2006: 8-9).

Em "Metamorphosis of the Cassowaries", na seção dedicada à transformação dos tipos de máscaras usadas pelos Umedas, Gell (1975) apresenta um exemplo interessante do uso de diagramas. Nas palavras do autor, "O argumento desta seção é expresso em termos visuais: para seguí-lo, é necessário referir-se às figuras que mostram os vários tipos de penteados e máscaras." (Gell 1975: 279). Entre os Umedas, o ciclo de vida masculino era marcado por mudanças de penteado e cada estilo expressava os estágios desse progresso: cabelo curto (controlado ou não) e cabelo longo (controlado ou não). Dessa elaboração da cabeça humana iriam partir os diferentes estilos e tipos de máscaras. Para resumir o seu argumento, Gell dispõe de um 'fluxograma' justapondo os vários tipos de máscaras de acordo com a sua sequência temporal implícita e 'processual"' (Gell 1975: 297-308). Aqui, nota-se tanto o desafio de inscrever uma transformação temporal em um diagrama que ganha o caráter de fluxograma, quanto a observação explícita feita pelo autor de que a seção em questão é concebida em termos visuais. Ou seja, o desenho-diagrama não era exterior à formulação do autor que buscava trazer uma dinâmica própria ao diagrama por meio do fluxograma.

Retomando o argumento de Grimshaw e Ravetz sobre a presença/ausência das imagens na antropologia (2005: 3), essas autoras ainda descrevem as contradições internas da antropologia moderna em aceitar ou não recursos visuais como fonte de pesquisa e exposição do conhecimento. Destacam que foi somente a partir da década de 70 que a antropologia visual se firmou como uma sub-disciplina, tendo como marco a publicação de "Principles of Visual Anthropology" de Paul Hocking in 1975. No Brasil atual, os reflexos mais evidentes do espaço 
conquistado pela antropologia visual são os prêmios Pierre Vergé de Filme Etnográfico (em sua XI edição) e de Ensaio Fotográfico (em sua VIII edição), concedidos durante a bienal Reunião Brasileira de Antropologia, em que não há nenhuma menção ao desenho.

Aqui, não é o caso de definir a posição do desenho em relação à antropologia visual, mas de observar a existência de práticas que conversam entre si mantendo-se separadas. E ainda, de perceber as oscilações entre presença e ausência que as imagens, em suas diversas formas, sofreram ao longo do tempo na antropologia. De todo modo, vale salientar que, se o desenho participa de alguma forma da gênese da antropologia visual, é certo que não acompanha os seus desdobramentos. $\mathrm{E}$ ao que tudo indica, embora haja uma série de pontos convergentes entre registros que são distintos do texto - como é o caso do desenho, da fotografia e do filme - as diferenças entre essas práticas persistem.

Inclusive, autores como Taussig enfatizam as qualidades do desenho contrastando-o com a fotografia. Parafraseando Berger, Taussig destaca a passagem do tempo que se evidencia ao longo do desenhar; ao contrário do que ocorre com a fotografia que congelaria os eventos (2011: $21)^{10}$. Ainda: Taussig considera que o poder do desenho está em revelar exatamente aquilo que escapa à fotografia - como a possibilidade de desenhar acontecimentos anteriores ou a possibilidade de desenhar a própria imaginação (2011: 31). No mesmo sentido, Ballard observa que na ocasião em que Haidy Geismar e Anita Herle repatriaram imagens de John Layard aos Malakula, 200 fotografias foram reproduzidas e apenas 3 desenhos, quais sejam: "um mapa, um desenho de areia e uma vista panorâmica da área de dança na Ilha Vao, todos exemplos de imagens que a fotografia falha em capturar adequadamente, e para os quais os antropólogos comumente recorreram ao desenho.” (Ballard, 2013: 139-140).

Ou seja, embora digno, o lugar ocupado pelo desenho na antropologia é justamente aquele em que a fotografia falha? Em outras palavras: é esse o desenho permitido pela antropologia? Uma outra pergunta seria: será que a evolução técnica é suficiente para descrever uma espécie de substituição do desenho pelo fotografia - quando sabemos o quão difícil era transportar equipamentos pesados para o trabalho de campo?

Se o desenho será localizado junto à antropologia visual no futuro é uma questão que não cabe responder aqui. Entretanto, enquanto a antropologia visual conquistou o seu lugar ao sol - não tão brilhante como critica Martins (2012) - , o mesmo não ocorreu com o desenho que ainda precisa se firmar e se legitimar em espaços institucionais - como é o caso dos prêmios, dos artigos científicos, dos grupos de discussão, dos cursos universitários e do desenvolvimento das habilidades dos antropólogos.

10 Merleau-Ponty recupera uma ideia semelhante de Rodin ao expressar uma crítica à fotografia. Para Rodin, a pintura que representa cavalos cavalgando no espaço - o Derby de Epson de Géricault - é mais verdadeira que o instante congelado da fotografia que, por sua vez, revela a posição correta das patas, mostrando, porém, um cavalo que parece saltar no mesmo lugar. A frase de Rodin é a seguinte: "É o artista que é verídico, e a foto que é misteriosa, pois, na realidade, o tempo não pára.” (Rodin apud Merleau-Ponty 2004: 41). 


\section{Desenho e antropologia ao redor do século XXI}

$\mathrm{Na}$ atualidade, há um número crescente de produções em que o desenho tem se destacado como método de pesquisa/forma de exposição do conhecimento, como atestam os trabalhos de Newman (1998), Colloredo-Mansfeld (1999, 2011), Ramos (2004, 2009, 2010, 2015), Hendrikson (2008 e 2010), Taussig (2009, 2011), Ingold (2011a, 2011b, 2013), Causey (2012), Olivar (2007, s/ data, 2010), Kuschnir (2012 e 2014), Azevedo (2013, 2014 e no prelo), Geismar (2014), Borseman (2014), Ballard (2013), Azevedo e Schroer (no prelo) e Azevedo e Ramos (2016). Além disso, outros trabalhos dão corpo à literatura sobre o tema de forma mais ou menos indireta, tais como Afonso e Ramos (2004), Lagrou (2007), Wright (2008), Gunn (2009) e Grimshaw e Ravetz (2015).

Como foi esclarecido desde o princípio, privilegiamos aqui reflexões e desenhos feitos por antropólogos, ainda que eventualmente tais desenhos surjam em diálogo com os desenhos das pessoas com quem trabalhamos, sendo esse o caso discutido por Colloredo-Mansfeld (2011) sobre a pintura Tinguan. Entretanto, mesmo circunscrevendo o desenho àqueles produzidos principalmente por antropólogos em torno do século XXI, a tarefa de catalogar a diversidade de investimentos segue problemática.

Para alguns, o desenho é um verbo, um fazer, um processo, uma metodologia de pesquisa; para outros, o desenho é um resultado de pesquisa e uma forma, inclusive, de apresentá-la; para muitos, o desenho é ambas as coisas. Há também variações naquilo que provisoriamente poderíamos chamar de estilo: alguns desenham em cadernos, considerando seriamente a diferença existente no desenho feito num suporte privado e móvel, quando destaca-se também o "princípio de narratividade" (Ramos 2008: 153) presente na sequência de folhas desenhadas; outros inspiram-se na arte sequencial para construir uma narrativa desenhada, ou seja, um tipo de desenho distinto dos esboços e dos desenhos feitos em diários, pois geralmente produzidos como uma narrativa gráfica nada ou pouco casual; há também quem se dedique somente ao esboço, sem qualquer pretensão estilística ou narrativa; outros demonstram conhecimento técnico do desenho - um conhecimento resultante, invariavelmente, da prática diletante -, em contraposição àqueles que não demonstram muita destreza ao desenhar, não sendo muito simples, nem útil, enquadrar os estilos daí derivados.

Por fim, há toda uma infinidade de possibilidades relacionadas ao próprio desenho que pode ser feito com o apoio de diversos materiais (canetas comuns ou especiais, aquarelas, lápis, etc.), ser produzido em diferentes suportes (folhas soltas, cadernos, tablets, etc.) e, além disso, prescindir da palavra, nascer da palavra ou dar origem à palavra. Para darmos um exemplo exterior à antropologia, temos Dostoiévski, que desenhava como parte de seu processo criativo literário em seus manuscritos, rompendo as barreiras entre escrita e desenho ao transformá-los num continuum, colocando-os em interação em verdadeiras composições gráfico-verbais (Barsht, 2008).

Apontada essa variedade, o material apresentado a seguir se caracteriza pela liberdade: cada autor demonstra um estilo próprio e tira conclusões particulares de suas experiências que são diversas por natureza. Ou melhor, talvez sejam diversas pelo fato do desenho ter seguido certas tendências e estilos no passado - como o desenho anatômico e de cultura material, por exemplo -, mas se encontrar numa fase em que não é normatizado em termos de estilo e também não é formalizado em termos metodológicos ou expositivos, o que pode ser entendido como o lado 
bom de sua marginalização atual. Ao recuperarmos tais trabalhos, o objetivo é apontar as diversas possibilidades do desenho que podem servir de inspiração para outros antropólogos. O ideal aqui seria apresentar os desenhos de cada autor, uma tarefa, entretanto, impossível.

Antes de percorrer os trabalhos de antropólogos que desenham, apresento um breve debate em torno das ideias que orbitam o desenho e o desenhar como uma prática na antropologia na atualidade. Para tanto, começo com a abordagem de Ingold sobre a "graphic anthropology" ou "antropologia gráfica" destacada em seus últimos trabalhos (2011a, 2011b, 2013). Ingold localiza o desenho como um "modo de pensar" atrelado ao "fazer", em que advoga-se um "conhecer por meio do fazer" e um "conhecer desde dentro". Conforme o autor (Ingold 2013: 126-129), como processo de pensar-fazendo, o desenho seria considerado anti-totalizante - não se comprometendo com a cobertura total da superfície, nem com qualquer ideia de acabamento. Além disso, expressaria tempo e movimento: como a dança e a música, o desenho não reteria o tempo, fluiria com ele em sua execução.

Para Ingold, o desenho se distinguiria como técnica de observação inigualável e seria considerado transformador, na medida em que prescreve uma relação do pesquisador com aquilo que desenha, pois o desenho não corresponde à projeção de uma ideia no papel, nem a uma narrativa feita a posteriori, e sim, surge, junto com aquilo que se observa (Ingold 2013: 126-129). O desenho também seria percebido como uma forma de conectar as experiências de observação e de descrição que, em geral, encontram-se separadas - temporal e espacialmente - na produção final de nossos trabalhos (Ingold 2011b: 9).

Em "I swear I saw this. Drawings in fieldwork notebooks, namely my own", contribuição de Taussig (2011) à relação entre desenho e antropologia, há igualmente um apanhado de reflexões em defesa do desenho como "modo de pensar" e de "fazer" antropologia. Entretanto, Taussig baseia suas reflexões nos desenhos que fez em trabalho de campo na Colômbia - o que traz um sabor distinto a suas considerações, pois não se trata de uma teoria sobre o desenho, mas do desenho como uma prática da qual seguem certas percepções.

Por que desenhar no trabalho de campo? Uma resposta curta de Taussig poderia ser "É bom andar com duas pernas ao invés de uma” (Taussig 2011: 30). Taussig relaciona o desenhar ao escrever ao longo de suas duras críticas ao processo paralisante da escrita e se refere a um dos últimos ensaios de Roland Barthes - "One always fails in speaking of what one loves" - para se perguntar se o desenho poderia ser uma forma de contornar a afasia à qual somos levados quando sentimos (Taussig 2011: 17). Taussig quer dizer que a escrita no caderno de campo pode empurrar a realidade para um lugar cada vez mais inalcançável, como se transformasse coisas belas em feias ao distanciar o sentido daquilo que queremos dizer (Taussig 2011: 19). Em sua perspectiva, é exatamente o oposto o que ocorre com o desenho, já que ele considera a possibilidade de olharmos para a imagem como um quebra cabeça em que há segredos e insights por serem decifrados, algo que não irá depender da qualidade do desenho (Taussig 2011: 20).

Como exemplo da sua relação com o desenho em trabalho de campo, Taussig descreve a experiência de desenhar a embarcação fantasma de Julio Reyes subindo o rio à noite na Colômbia. Ele ouvira falar sobre essa história - que, aliás, jamais poderia ser fotografada - e resolveu se deter nos reflexos do rio noturno. A tentativa de representar o barco, o brilho das lâmpadas de gasolina e as cabanas invertidas no rio deixaram-no com uma impressão péssima de seu próprio desenho. Porém, ele relata que olhou para aquelas cores, para a noite e o rio como 
se nunca os tivesse visto antes. Ao final, Taussig se pergunta se existiria uma outra atividade como desenhar - que tão bem recompensaria as falhas? Para ele, ao contrário do que ocorre com a escrita, "esses são sapos que se tornam flores" (Taussig 2011: 31).

Apesar da facilidade com que Taussig relata a sua falta de habilidade em desenhar, a maioria dos antropólogos não só se sente desconfortável em mostrar os seus desenhos como, em geral, não vê motivos para desenhar. Aparentemente, no entanto, todas as pessoas têm a capacidade de desenhar, embora a maioria considere que não. Uma das razões que Ingold encontra para a rejeição ao desenhar relaciona-se a uma certa noção do "fazer" como projeto, ou seja, quando uma ideia preconcebida é projetada para ser posta no papel (Ingold 2011a: 177). Seguindo uma perspectiva que se opõe a essa, Ingold traz a experiência de Marion Milner descrita no livro "On not being able to paint", quando ela se sentia péssima diante de sua inabilidade para desenhar, até que experimentou uma outra abordagem. Ao invés de tentar transpor, sem êxito, o que via para o papel, deixou a sua mão seguir para onde quer que fosse, sem qualquer ideia preconcebida de como isso iria terminar (Milner apud Ingold 2011b: 17-18). Assim, ela conseguiu desenhar. A ênfase aqui está em um certo tipo de desenho: aquele menos comprometido com a forma final e mais com o processo de desenhar.

Concordar com a ideia de Ingold de que todos podem desenhar ou de Taussig de que as falhas do desenho são recompensadoras, não significa que não deva haver um investimento, uma dedicação à prática do desenho. Como é mostrado por Kuschnir (2014), para algumas pessoas não é tão simples começar a desenhar e no "Laboratório de Desenho e Antropologia" que a autora fez durante um semestre com estudantes de antropologia na Universidade Federal do Rio de Janeiro, diferentes técnicas foram apresentadas e praticadas. A ideia era de que os alunos desenvolvessem certas noções de desenho para que finalmente se sentissem confortáveis para desenhar como um recurso de pesquisa e forma de descrição na antropologia.

Assim, o desenho pode ser entendido como um processo, uma maneira de pensar, observar, conhecer, descrever e revelar menos comprometido com o resultado final - como mostram Ingold e Taussig. Ou, como uma técnica mais densamente trabalhada em cursos que enfatizam igualmente o desenho enquanto processo e, além disso, produto final, bem como o desenvolvimento das habilidades dos antropólogos - como mostra Kuschnir.

Posto isso, me volto, finalmente, para as experiências de antropólogos que desenham. $\mathrm{Na}$ atualidade, o trabalho que parece ser pioneiro na articulação entre narrativa desenhada e antropologia é "Prophecies, Police Reports, Cartoons and Other Ethnographic Rumors in Addis Ababa" de Newman (1998). Aqui, a autora compôs um artigo desenhado em que narrou a morte de um eremita na Etiópia. Influenciada pela narrativa pictórica etíope, pelos quadrinhos e a novela gráfica, este é um esforço exemplar na conjugação do desenho e da antropologia no formato de arte sequencial. Além disso, o uso de elementos da narrativa pictórica etíope na composição de Newman evidencia a busca de uma certa mimese entre o desenho da antropóloga e o mundo a que se refere.

Numa linha que segue a mistura entre quadrinhos, desenhos em sketchbooks e antropologia, temos os trabalhos de Ramos (2009, 2010 e 2015), ex-quadrinista e antropólogo. O livro "Histórias Etíopes, Diário de viagem" (Ramos 2010) corresponde ao início da pesquisa de Ramos na Etiópia e expressa suas primeiras impressões sobre o país. A preciosa introdução ao livro (já mencionada neste artigo), revela a própria relação do autor com o desenho e ainda in- 
dica a relação pretérita entre desenho e antropologia. Aqui, Ramos conjugou desenho e escrita feitos em diários, um estilo que o autor continuará a desenvolver em outros trabalhos, como é o caso de "Traços de Viagem" (2009), livro que reuniu desenhos e notas de campo em que viagem, turismo, pesquisa acadêmica, observação e imaginação se mesclaram. Em "Drawing the lines" (Ramos, 2004), existe uma reflexão mais profunda de Ramos a respeito da sua relação com o desenho e a antropologia que lhe permitiu pensar na ideia de diálogo intercultural (Ramos 2004: 149). Por fim, em seu artigo mais recente "Stop the Academic World, I Wanna Get Off in the Quai de Branly'. Of sketchbooks, museums and anthropology" (Ramos, 2015), Ramos produziu uma reportagem desenhada do museu francês, quando desenho e texto se misturaram no seu sketchbook. Neste último caso, não houve uma edição posterior de seu sketchbook. Para compor uma análise crítica da arquitetura e do acervo do Quai Branly, assim como de seus frequentadores durante um verão parisiense, Ramos apresentou um artigo que seguiu sua caligrafia e seus desenhos tal como surgiram em seu sketchbook.

Já o uso do desenho como uma metodologia de pesquisa foi apresentado por ColloredoMansfeld em uma reflexão sobre os desenhos que atravessaram o seu livro, "The native leisure class" (1999). Na passagem intitulada "Sketching as an Ethnographic Encounter" (ColloredoMansfeld 1999: 49-56), o autor justificou a sua opção por produzir desenhos realistas no trabalho de campo como uma forma de interlocução, embora nos tenha trazido motivos para acreditar que outras formas de representação sejam tão eficazes quanto essas, a depender de quem as interpreta. Esse é o caso das diferentes formas com que representou um tear. Em um exemplo, o desenho mostrou-se mais facilmente interpretado pelas pessoas mais velhas com quem trabalhou; em outro, pelas mais novas. Entretanto, é num terceiro exemplo menos explorado pelo autor, em que figura e fundo se contrapõe, que eu mesma percebi algo como uma trama ao fundo que me trouxe a sensação ou a tessitura das linhas emaranhadas produzidas pelo tear.

Em outra oportunidade, "Space, line and story in the invention of an Andean aesthetic", Colloredo-Mansfeld (2011) seguiu desenhando e refletindo sobre o desenho como uma forma de interlocução. Entretanto, aqui o autor descreveu mais diretamente como o ato de desenhar pode ser uma ferramenta etnográfica de exploração. Neste caso, sua investigação se voltou para a pintura Tinguan nos Andes. Colloredo-Mansfeld usou explicitamente o desenho em oficinas com pintores Tinguan para pensar a perspectiva - uma noção que parecia ser desconhecida ali, já que a pintura Tinguan era sempre feita em um único plano, quando elementos escalonados na paisagem encontravam-se todos reunidos no desenho. Após as oficinas em que ele e os pintores Tinguan re-desenharam certos motivos, Colloredo-Mansfeld percebeu que a ausência de perspectiva era, na verdade, uma opção estética que tornava possível a reunião de elementos importantes para os Tinguan no mesmo plano, ao invés de escamoteá-los por meio da profundidade trazida pela perspectiva.

Um exemplo mais casual, porém não menos importante de percepções que surgem no trabalho de campo por meio do desenho, foi trazido por Causey (2012) no artigo "Drawing flies: artwork in the field" (2012). Causey descreveu como algo aparentemente banal, como desenhar insetos, particularmente um besouro, o levou à discussão de temas até então evitados por seu interlocutores em Sumatra, na Indonésia. Ali, Causey pesquisava o impacto do turismo entre os Toba Bataks e uma das questões que o intrigava era o consumo ilegal de cogumelos alucinógenos fornecidos pelos Bataks aos turistas. Imaginados por Causey como uma fonte de poder xamânico no passado, os usos do cogumelo poderiam ter se transformado com as leis e o turismo ocidentais. Foi pelo interesse despertado em seus interlocutores ao verem, casualmente, 
os desenhos de insetos produzidos pelo autor que o tema da pureza/impureza veio finalmente à tona, assim como o poder daquilo que nasce e se alimenta dos excrementos, como os besouros e os cogumelos. Para Causey, a qualidade de seus desenhos foi o menos importante, sendo a experiência de desenhar e o objeto desenhado aquilo que considerou fundamental para despertar uma conversa desejada, porém inesperada.

O trabalho com prostitutas em Porto Alegre desenvolvido por Olivar é, por sua vez, um exemplo bastante interessante de um esforço do autor em pensar formas metodológicas que estejam em sintonia com as pessoas com quem trabalhamos (Olivar s/data: 1). Em "Dibujando putas”, Olivar (2007) abre seu artigo questionando nossa preparação para o trabalho de campo como algo focado especialmente na escuta, deixando de lado outras formas de nos relacionarmos com a realidade. Assim, o autor escreve que: "(...) quando a porta do elevador se abriu, eu não estava preparado para outra coisa que não fosse escutar. Não estava preparado para ver, porém o mundo quase nunca necessita de nossa preparação.”(Olivar 2007: 1). Com essa constatação inaugural, Olivar reflete sobre os desenhos que fez durante o trabalho de campo, trabalho este que resultou numa tese de doutoramento recheada de desenhos (Olivar 2010).

Entre as questões levantadas por Olivar está o que ele considerou uma das complexidades de seu trabalho de campo com prostitutas, qual seja, a cumplicidade e clandestinidade femininas, apresentadas como um desafio a ser representado. Ao se deparar com fotografias de prostitutas cuja finalidade seria a de familiarizar o leitor, o que Olivar encontrou foram imagens de pobreza e marginalidade. Não que ele negasse tais características, entretanto, as mulheres com quem trabalhou "se arrumavam cuidadosamente para apagar as marcas de exclusão e pobreza" e sua experiência como observador "estava muito mais próxima de Bachelard, do filme "Pillow Book' e da arte barroca de Caravaggio, que dos registros de medicina forense" (Olivar 2007: 9). Assim, o autor se coloca a questão de como produzir imagens que não sejam desleais ao universo representado.

Em outro trabalho que tematiza o mesmo assunto, "Ethnographic drawings: some insights on 'prostitution, bodies and sexual rights"', Olivar (s/data) parte da crítica à câmera fotográfica como uma arma usualmente apontada para as prostitutas por policiais, repórteres, profissionais da saúde ou pervertidos. Com isso, o autor clama por um novo repertório de imagens que não negue a multiplicidade e complexidade da experiência de prostituição (Olivar s/data: 1). Para Olivar, os desenhos que produziu têm um investimento estético que fazem deles tanto uma expressão artística quanto uma ferramenta para análise nas ciências sociais (Olivar s/data: 1). São também uma reconstrução fenomenológica de sua experiência de campo e, o que é mais importante para o autor, fazem parte de um esforço maior de promover os direitos e a saúde sexuais (Olivar s/data: 1-2). Considerando a arte como uma ferramenta reconhecida quando o assunto é sexualidade, tanto em termos subjetivos quanto sociais, Olivar concluiu que por meio dela criam-se espaços em que é possível circular de formas novas e radicais (Olivar s/data: 2).

$\mathrm{Na}$ etnologia, dois trabalhos se destacam em termos de desenho: "A fluidez da forma" de Lagrou (2007) e "Ser en el sueño" de Wright (2008). O primeiro deles, embora não apresente maiores reflexões sobre o desenho como método de pesquisa ou forma de exposição do conhecimento, conta com diversos desenhos produzidos pela autora, além daqueles feitos pelos Kaxinawá com quem trabalhou. De forma bastante despretensiosa, Lagrou revela, por meio de um desenho e de uma anedota sobre a sua confecção que, em sua primeira viagem de barco ao grupo indígena com quem trabalhou, ela pôde antever a classificação das imagens, além da 
expressão e percepção visual Kaxinawa (2007: 117) - assuntos trabalhados ao longo de todo o livro. Já em "Dibujos", uma espécie de apêndice de "Ser en el sueño" (2008), Wright apresenta uma série desenhos feitos principalmente por seu interlocutor indígena Ángel, mas também por dois colegas de pesquisa, além dele mesmo. Tais desenhos foram conectados à cosmologia Toba no capítulo intitulado "Cosmografias", em que o autor apresenta o desenho como um técnica de pesquisa que superou os limites temáticos de suas perguntas, o levando a aprofundar as suas investigações especialmente sobre o mundo sobrenatural Toba e a compreender melhor os seres e as relações que não conseguia visualizar.

Já a interface entre desenho e mundo virtual foi abordada no artigo de Boserman (2014), "Entre grafos y bits", que reúne desenho, práticas digitais e investigação social como uma metodologia de análise de políticas de representação social. Partindo de uma tecnologia rudimentar como os cadernos e os desenhos, a autora passa por scanners, para chegar a sistemas de arquivo e armazenamento on line (Boserman 2014: 14). Nomeando seu trabalho de \#relatograma e \#coreograma, o primeiro seria um objeto digital formado por desenhos e palavras capazes de fixarem experiências e ideias em narrações gráficas não lineares (Boserman 2014: 10-12); enquanto o segundo seria o conjunto dos \#relatogramas em circulação, em compartilhamento na rede (Boserman 2014: 20).

O desenho foi trazido por Boserman como processo de documentação, inscrição e registro (Boserman 2014: 9) do qual parte o \#relatograma. Boserman apresenta uma morfologia dos \#relatogramas que devem conter, entre outras coisas: desenho dos participantes, perguntas ou reflexões em torno do assunto, informação do evento e referências que podem ampliar a discussão realizada ali (Boserman 2014: 15-16). Seu objetivo com os \#relatogramas é "oferecer uma vista parcial dos acontecimentos, das ideias, autores, visões expostas, de quem relata, escuta, dos imaginários depreendidos.” (Boserman 2014: 18), ou seja, quer dar conta da produção do conhecimento como um processo. Entretanto, quando os \#relatogramas estão em circulação transformando-se em \#coreogramas - é que a autora percebeu o potencial de seu método, como a produção de um tipo de memória digital e de imaginários gerados pela agregação (Boserman 2014: 21).

Por fim, como uma referência na relação entre desenho e antropologia no Brasil, temos Kuschnir, já mencionada anteriormente. Além de "Ensinando antropólogos a desenhar" (Kuschnir 2014), há um outro trabalho da autora que revela o seu interesse pelo processo de desenhar cidades do grupo Urban Sketchers (do qual ela mesma faz parte). Neste artigo, Kuschnir (2014) incluiu os seus próprios desenhos, além daqueles produzidos por membros do grupo estudado, transformando o desenho em objeto de investigação, método de pesquisa e apresentação dos resultados.

Não caberia discutir aqui as minhas próprias contribuições à relação entre desenho e antropologia, tendo em vista que o presente artigo é uma manifestação disto. Assim, apenas indico tais investimentos a seguir. Em "Um convite à antropologia desenhada”, escrevi sobre a possibilidade do desenho ser incorporado aos métodos e técnicas de pesquisa da antropologia com a ideia de que se não soubermos que podemos desenhar, talvez não o façamos (Azevedo 2016). Já em "Diário de campo e diário gráfico: contribuições do desenho à antropologia" (Azevedo no prelo) trouxe as contribuições do "diário gráfico" (Salavisa 2008 e 2014) para pensarmos que, além da escrita não precisar ser a única forma de notação em nossos diários de campo, podemos aprender bastante com os diários daqueles que desenham - suas técnicas e perspectivas. Em um 
trabalho feito a quatro mãos, "Drawing Close - on visual engagement in fieldwork, drawings and the anthropological imagination" (Azevedo e Ramos 2016), escrevemos sobre uma oficina de desenho que realizamos na University of Aberdeen junto com Ingold e a comunidade acadêmica local. Aqui debatemos o lugar que o desenho tem e pode vir a ter em nossas pesquisas atuais e apresentamos os desenhos produzidos ao longo daquele encontro. Em outro trabalho colaborativo, "Weathering - a graphic essay" (Azevedo e Schroer no prelo), apresentamos uma narrativa gráfica-antropológica em forma de arte sequencial sobre a relação entre falcoeiros e falcões. Além desses trabalhos mais recentes, a minha própria tese "Conquistas cosmológicas: pessoa, casa e casamento entre os Kubheka de KwaZulu-Natal e Gauteng” (Azevedo 2013) conta com um Caderno de Imagens que apresenta a maior parte dos desenhos que fiz em campo na África do Sul. Por sua vez, "Desenhos na África do Sul: Desenhar para ver, para dizer e para sentir" (Azevedo 2014) é um pequeno ensaio visual que também apresenta alguns dos desenhos produzidos durante o trabalho de campo que originou a minha tese de doutoramento.

\section{ComentáRios finais}

A fim de conduzir a investigação sobre desenho e antropologia, nos guiamos por perguntas bastante genéricas, tais como "por que os antropólogos desenhavam no passado?" e "por que pararam de fazê-lo?". Vimos que o desenho foi uma técnica de pesquisa bastante utilizada na virada do século XX - a exemplo de Miklouho-Maclay e Deacon - que, entretanto, parece não ter sido formalmente difundida como uma das habilidades dos antropólogos para o trabalho de campo (Geismar 2013), com exceção da menção ao ensino do desenho na antropologia russa (Makar'ev 1928).

A oscilação entre apropriação e recusa das imagens ao longo da história da antropologia foi descrita por autores como Gell (1999) e Grimshaw e Ravetz (2005). Neste percurso, o desenho pareceu compartilhar os mesmos dilemas enfrentados pelo filme e a fotografia na gênese da antropologia visual, sem participar, entretanto, do processo de institucionalização desse campo da antropologia. $\mathrm{Na}$ atualidade, percebemos que a convergência entre desenho e antropologia visual tem operado mais pela diferença que pela semelhança, quando o pensamento que orienta e legitima o desenho como forma de fazer antropologia tem, muitas vezes, a fotografia como contraste (Taussig 2011; Ballard 2013) ${ }^{11}$.

"Por que alguns antropólogos desenham atualmente e quais os efeitos dessa prática em suas metodologias/resultados de pesquisa?" foram as perguntas que nos serviram como guias para pensarmos o momento atual. Em síntese, percebemos uma profusão de motivos e justificativas para desenhar inversamente proporcional à diversificação de estilos e metodologias que podem servir como inspiração para outros antropólogos. Tendo em vista a marginalização do

11 Para uma crítica aos limites da abordagem de Ingold e Taussig com relação ao desenho como um verbo, ou seja, como um processo de pesquisa que considera a forma final subsidiária, ver Grimshaw e Ravetz (2015). Em "Drawing with a câmera? Ethnographic film and transformative anthropology", as autoras lançam mão de uma reflexão que equipara o processo de filmar ao processo de desenhar, sem evitar o fato de que o filme compromete-se inevitavelmente com o enquadramento, enquanto o desenho permanece aberto. É somente ao considerar os rendimentos de ambas as práticas que as autoras pensam na possibilidade de uma visão mais radical da antropologia, na qual esta poderá ser considerada como uma "prática de fazer imagens" (Grimshaw e Ravetz 2015: 271). 
desenho na antropologia, não é estranho constatar o misto de empolgação e dúvida que acompanha a espécie de novidade trazida pela inserção do desenho na prática antropológica.

Entretanto, a mesma marginalização - cujo efeito é libertador, gerando múltiplos investimentos de difícil catalogação e em ampla profusão - apresenta também outras faces. Por um lado, há pouco conhecimento de uma prática mais comum do que se imagina na história da antropologia - o que faz do desenho uma novidade velha. Por outro lado, a marginalização também pode ter um efeito paralisante, quando não sabemos ou não nos sentimos seguros quanto ao fato de que, sim, podemos desenhar como parte integrante de nossas pesquisas. Desse modo, este artigo buscou suprir, de forma ainda parcial, uma lacuna no que concerne ao desenho feito por antropólogos, recuperando essa relação histórica e os trabalhos que tratam desse assunto ao redor do século XXI com vistas a um futuro que parece promissor.

\section{ReferênCias Bibliográficas}

Afonso, Ana Isabel, Manuel João Ramos. 2004. "New Graphics for Old Stories: Representation of local memories through drawings". Pp. 66-83 in Working Images: Visual Research and Representation in Ethnography, edited by A. I. Afonso, L. Kurti e S. Pink. London: Routledge.

Azevedo, Aina. 2013. "Conquistas cosmológicas: Pessoa, casa e casamento entre os Kubheka de KwaZulu-Natal e Gauteng." Tese de Doutorado. Programa de Pós-Graduação em Antropologia Social. Brasília. 346 f.

2014. "Desenhos na África do Sul: Desenhar para ver, para dizer e para sentir." Pós Revista Brasiliense de Pós-Graduação em Ciências Sociais, 5 (13): 221-226. (http://periodicos.unb.br/index.php/revistapos/article/view/12594)

.2016. "Um convite à antropologia desenhada." METAgraphias: metalinguagem e outras fguras, v. 1 n.1 (1): 194-208. (http://periodicos.unb.br/index.php/metagraphias/article/ view/15821)

. no prelo. "Diário de campo e diário gráfico: contribuições do desenho à antropologia". Altera Revista de Antropologia.

Azevedo, Aina e Sara Asu Schroer. no prelo. "Weathering - a graphic essay."

Azevedo, Aina e Manuel João Ramos. 2016. "Drawing Close - on visual engagement in fieldwork, drawings and the anthropological imagination". Visual Ethnography.

Ballard, Chris. 2013. "The Return of the Past: On Drawing and Dialogical History”. The Asia Pacific Journal of Antbropology, 14:2, 136-148. (http://www.tandfonline.com/doi/abs/10.10 80/14442213.2013.769119\#.V2byzFe2Dwc)

Barbosa, Andréa, Edgar Teodoro da Cunha. 2006. Antropologia e Imagem. Rio de Janeiro: Zahar. Barnard, Alan, Jonathan Spencer. 2010. “Time and Space.” Pp. 689-693 in The Routledge Encyclopedia of Social and Cultural Anthropology, edited by A. Barnard, J. Spencer. London and New York: Routledge.

Barsht, Konstantin. 2008. “Dostoevsky: drawing as writing,” Item [Online]. (www.item.ens.fr/ index.php?id=223406)

Boserman, Carla. 2014. "Entre grafos y bits". Obra digital - Revista de Comunicación, Narrativas y diseño digital, número 6, fevereiro. (http://revistesdigitals.uvic.cat/index.php/obradigital/ article/view/33) 
Caiuby Novaes, Sylvia. 2004. “O uso da Imagem na Antropologia.” Pp.113-119 in Ofotográfico, edited by E. Samain. São Paulo: Hucitec e SENAC.

Causey, Andrew. 2012. "Drawing flies: artwork in the field." Critical Arts, 26 (2), pp. 162-174. (http://www.tandfonline.com/doi/abs/10.1080/02560046.2012.684437)

Colloredo-Mansfeld, Rudi. 1999. "Sketching as an Ethnographic encounter." Pp. 49-56 in Native Leisure Class: consumption and cultural creativity in the Andes. The University of Chicago Press: Chicago. 2011, "Space, line and story in the invention of an Andean aesthetic". Journal of Material Culture, 16 (1): 3-23. (http://mcu.sagepub.com/content/16/1/3.abstract)

Evans-Pritchard, Edward. 2002. Os Nuer. Uma descrição do modo de subsistência e das instituições politicas de um povo nilota. São Paulo: Editora Perspectiva.

Freud, Sigmund. 2015. Obras completas, volume 13: conferências introdutórias à psicanálise (19161917). São Paulo: Companhia das Letras.

Focillon, Herni. 2012. Elogio da mão. Instituto Moreira Sales, Rio de Janeiro. Disponível em: https://issuu.com/ims_instituto_moreira_salles/docs/elogiodamao_07.

Geismar, Haidy. 2014. "Drawing it Out". Visual Anthropological Review, 30 (2): 96-113. (http:// onlinelibrary.wiley.com/doi/10.1111/var.12041/full)

Gell, Alfred. 1975. Metamorphosis of the Cassowaries. Used Society, Language and Ritual. London: The Athlone Press. . 1999. The art of anthropology - Essays and Diagrams. Edited by E. Hirsch. Londres: The Athlone Press.

Grimshaw, Ann, Amanda Ravetz. 2005. “Introduction: Visualizing Anthropology.” Pp. 1-17 in Visualizing Anthropology, edited by A. Grimshaw and A. Ravetz. Bristol: Intelect. . 2015. "Drawing with a camera? Ethnographic film and transformative anthropology." Journal of the Royal Anthropological Institute, vol. 21, issue 2: 255-275. (http://onlinelibrary. wiley.com/doi/10.1111/1467-9655.12161/abstract)

Gunn, Wendy. 2009. Fieldnotes and Sketchbooks: Challenging the boundaries between descriptions and processes of describing. Edited by W. Gunn. Frankfurt: Peter Lang.

Hendrikson, Carol. 2008. "Visual Field Notes: Drawing Insights in the Yucatan". Visual Anthropology Review, 24 (2): 117-132. (http://onlinelibrary.wiley.com/doi/10.1111/j. 1548-7458.2008.00009.x/abstract)

. 2010. "Ethno Graphics: Keeping Visual Field Notes in Vietnam". Expedition, Vol 52, n 1: 31-39. (http://www.penn.museum/documents/publications/expedition/PDFs/52-1/ Ethno-Graphics.pdf)

Ingold, Tim. 2011a. Being Alive - Essays on movement, knowledge and description. London and New York: Routledge.

. 2011b. "Prologue." Pp. 1-20 in Redrawing Anthropology. Materials, Movements, Lines, edited by T. Ingold. England: Ashgate.

2013. Making. Anthropology, archeology, art and architecture. London and New York: Routledge.

Kuschnir, Karina. 2012. "Desenhando Cidades”. Sociologia E' Antropologia. Vol. 02.04: 295314. (http://revistappgsa.ifcs.ufrj.br/wp-content/uploads/2015/05/14-ano2-v2n4_registro_karina-kuschnir.pdf)

2014. "Ensinando antropólogos a desenhar: uma experiência didática e de pesquisa". Cadernos de Arte e Antropologia 3(2): 23-46. (https://cadernosaa.revues.org/506?lang=en)

Lagrou, Els. 2007. A fluidez da forma: arte, alteridade e agência em uma sociedade amazônica (Kaxinawa, Acre). Rio de Janeiro: Topbooks. 
Makar'ev, Sergei A. 1928. Polevaia etnografiia. Kratkoe rukovodstvo i programma dlia sbora etnograficheskikh materialov v SSSR. Moscow.

Martins, Humberto. 2012. "Sobre o lugar e o uso das imagens na antropologia: notas críticas em tempos de audiovisualisação do mundo.” Etnográfica, vol.17(2): 395-419. (http://www. scielo.mec.pt/scielo.php?script=sci_arttext\&pid=S0873-65612013000200008)

Merleau-Ponty, Maurice. 2004. O olho e o espirito. São Paulo: Cosac\&Naify.

Newman, Deena.1998. "Prophecies, Police Reports, Cartoons and Other Ethnographic Rumors in Addis Ababa”. Etnofoor, vol. 11 (2): 83-110. (https://www.jstor.org/stable/25757941?seq=1\#page_scan_tab_contents)

Olivar, José Miguel. s/ data. Ethnographic drawings: some insights on "prostitution, bodies and sexual rights" (http://www.sxpolitics.org/wp-content/uploads/2009/06/artigo-dibujos_ze_final.pdf)

2007. "Dibujando Putas: reflexiones de una experiencia etnográfica con apariciones fenomenológicas." Pp. 54-84 Revista Chilena de Antropologia Visual (10), Santiago de Chile. (http://www.rchav.cl/imagenes10/imprimir/nieto.pdf)

2010. “Guerras, trânsitos e apropriações: políticas da prostituição feminina a partir das experiências de quatro mulheres militantes em Porto Alegre". Tese defendida no Programa de Pós-graduação em Antropologia Social da Universidade Federal do Rio Grande do Sul. $385 \mathrm{f}$.

Ramos, Manuel João. 2004. "Drawing the lines - The limitation of intercultural ekphrasis." Pp. 147-156 in Working Images: Visual Research and Representation in Ethnography, edited by A. I. Afonso, L. Kurti e S. Pink. London: Routledge. 2008. "Portugal. 1960." Pp. 152-157 in Diários de Viagem: desenhos do quotidiano, edited by E. Salavisa. Lisboa: Quimera Editores.

2009. Traços de Viagem. Lisboa: Bertrand Editora. 2010. Histórias Etíopes, Diário de viagem. Lisboa: Tinta da China.

2015. "Stop the Academic World, I Wanna Get Off in the Quai de Branly. Of sketchbooks, museums and anthropology", Cadernos de Arte e Antropologia, 4 (2): 141-178. (https://cadernosaa.revues.org/989)

Salavisa, Eduardo. 2008. Diários de Viagem - desenhos do quotidiano, edited by E. Salavisa. Lisboa: Quimera Editores.

.2014. Diários de Viagem 2 - desenhadores-viajantes, edited by E. Salavisa. Lisboa: Quimera Editores.

Taussig, Michael. 2009. "What Do Drawings Want?" Culture, Theory and Critique, vol. 50, issue 2-3: 263-274. (http://www.tandfonline.com/doi/abs/10.1080/14735780903240299?journalCode $=$ rctc20\#.V2cPV1e2DaY)

2011. I swear I saw this. Drawings in fieldwork notebooks, namely my own. Chicago and London: The University of Chicago Press.

Wright, Pablo. 2008. Ser en el sueño: Crónicas de historia y vida toba. Buenos Aires: Editorial Biblos.

\section{DRAWING AND ANTHROPOLOGY: HISTORICAL AND CURRENT RECOVERY}

Why did anthropologists make use of drawings and why did they stop doing so? This article seeks to recount the history of drawing and its regimes of visibility in the course of anthropology's own histo$r y$, and discusses the relation between drawing and anthropology at the turn of the 21st Century. As 
Ballard noted, we are witnessing a "graphic turn" in anthropology. The fact that a number of anthropologists are showing a renewed interest in drawing leads back to the author's preliminary question: why do anthropologists (still) use drawing in their fieldwork practice, and to what effect in terms of methodology and research findings? By discussing these questions, the author seeks to shed some light on the past, present and, eventually, future direction of the practice of drawing within that of anthropological.

Keywords: drawing, graphic anthropology, methodology, visibility

Recebido em: 2016-02-07

Aceitado em: 2016-07-05 